\title{
An Improved Optically Based PD Detection System for Continuous On-line Monitoring of HV Cables
}

\author{
Y. Tian, P. L. Lewin \\ The Tony Davies High Voltage Laboratory \\ University of Southampton \\ Southampton, Hampshire SO17 1BJ, UK \\ J. S. Wilkinson \\ Optoelectronics Research Centre \\ University of Southampton \\ Southampton, UK \\ G. Schroeder \\ Südkabel GmbH \\ Mannheim, Germany \\ S. J. Sutton \\ National Grid Transco plc \\ Warwickshire, UK \\ and S. G. Swingler \\ The Tony Davies High Voltage Laboratory \\ University of Southampton \\ Southampton, Hampshire SO17 1BJ, UK
}

\begin{abstract}
An optically-based remote sensing technique using a laser source, polarization scrambler, standard single mode fibers, fiber polarizer, electro-optic (EO) modulator and optical receiver, for continuous on-line monitoring of partial discharges (PD) in high voltage cable joints is proposed. Both the fiber polarizer and EO modulator, which are placed near cable joints, are passive without any power requirements. An EO modulator with no electrical bias, which operates close to the half-intensity point, was used and proved to have much better light transmission performance and higher measurement sensitivity than the bias modulator approach investigated earlier. Various multiplexing techniques including optical switches and a fused fiber coupler have been investigated in order to implement multi-channel monitoring so that one laser source can be used to provide light to several fibers. The revised PD optical remote sensing technique has been applied to practical PD measurements on both $132 \mathrm{kV}$ cable joint at the University of Southampton in the UK and $400 \mathrm{kV}$ cable joints at Südkabel GmbH in Germany. Obtained results have verified the principle and demonstrated the effectiveness of the developed technique.
\end{abstract}

Index Terms - Partial discharge, electro-optic modulator, optical remote sensing, continuous on-line monitoring, high voltage cable joints, capacitive coupler.

\section{INTRODUCTION}

$\mathrm{P}$ ARTIAL discharge (PD) activity is a prominent indicator of insulation defects. PD conven-

Manuscript received on 23 November 2004, in final form 24 May 2005. tional electrical measurement has been used for many years as a non-destructive off-line testing technique for insulation evaluation. Conventional PD measurement can detect the permissible discharge quantity expressed as an apparent charge, but it is not suitable for online applications due to its requirements for a coupling capacitor etc. 
Online PD measurements provide information about insulation faults under operational stress or defects introduced during transportation or installation. XLPE cable itself has undergone manufacturing quality control as well as PD testing at the factory before delivery. Defects such as particles and voids have been removed. For this reason on-line PD monitoring systems for cables should predominantly cover the accessories, which are more prone to problems due to the installation procedure and subsequent operational stresses.

The likelihood of a fault occurring within a HV transmission cable system can be described as the 'bath-tub' effect. Initially, fault likelihood is high mainly due to problems associated with installation. This can be minimized and removed by performing a series of after-laying tests. Then for many years there is minimal likelihood of fault, mainly because of the strict production and quality controls of cable manufacturers. After many years in service, i.e. 30-40 years, the likelihood of a cable fault rises again, due to factors such as dielectric ageing, over-voltage operations, repetitive thermal cycling, growth of electrical trees and water trees. Continuous on-line monitoring can provide information about progressing degradation or deterioration under normal operational stresses, thus reducing the likelihood of an occurrence of breakdown. Breakdown of a cable circuit can lead to severe economic losses for the system operator and severe disruption for customers. Therefore even for the period of low fault likelihood it is still advisable to have continuous on-line monitoring in order to detect any spontaneous fault condition that may cause the occurrence of breakdown. Additionally, the measured data and experience obtained over this time will be valuable for condition assessment of the system as it ages. Considering that many $\mathrm{HV}$ cable circuits are buried, it is advantageous to install data transmission links such as optic fibers and compact passive sensors for continuous on-line monitoring, at the time the cables are buried, ensuring that on-line PD monitoring is available during the whole of the system lifetime.

It is important to establish the data acquisition, transmission and processing methodologies for continuous online PD monitoring [1]. Data acquisition for PD detection in cable systems usually involves non-conventional electrical coupling techniques including capacitive couplers [2-6]; screen interruptions [6]; inductive high frequency current transformers (HFCT) either around the cable itself [7] or the earth connection [3]; directional couplers [8]; and foil electrodes on cable joints [9]; as well as acoustic emission (AE) techniques [3, 10]. Electrical coupling techniques work across various frequency ranges from a few $\mathrm{MHz}$ to several hundred MHz. An effective PD sensor should be compact and easy to install, with a good signal to noise ratio and sensitive to PDs of a few $\mathrm{pC}$, and potentially capable of expressing discharge quantity in $\mathrm{pC}$. The acoustic emission technique has the advantage of being immune from electrical interference. However, acoustic emission attenuation within HV cables significantly reduces measurement sensitivity and makes it impossible to calibrate. AE techniques are more suited for PD monitoring in power transformers, switchgear or GIS, where they are immune to the excessive electrical noise that may exist at the measurement site. The capacitive coupling technique has been extensively investigated by the authors and has proved to be an effective PD detection sensor for $\mathrm{HV}$ cables $[2,3,5,6]$.

High frequency components of PD signals are rapidly attenuated as they propagate along a HV cable. Sensors must be placed near to a PD source in order to obtain a good sensitivity. The detected PD signals from cable joints need to be transmitted over a long distance to the substation for further signal processing and analysis. Compared with transmission via coaxial electrical cables, data transmission via optical fiber has minimal attenuation $(0.2$ $\mathrm{dB} / \mathrm{km}$ ) and is immune from electrical interference. The optical fiber also provides electrical isolation of the measuring equipment. Generally, measured electrical signals are fed into an optical transmitter or an acquisition unit with digitizer and communication port, to be converted into optical signals, which are then transmitted over the typical optical fibre or digital fibre. However, either the optical transmitter or acquisition unit, which are placed nearby the PD sensors and cable joints, require a power supply to operate, although they can operate using battery power for a limited period of time. Consequently such systems are suitable for commissioning PD tests after cable laying, and are not really suitable for continuous online monitoring of PD activities in situations where there are no local power sources, for example buried cable circuits.

A novel PD continuous monitoring technique has been proposed by the authors [11]. The measurement mechanism applies capacitive coupler measured PD signals across a Lithium Niobate $\left(\mathrm{LiNbO}_{3}\right)$ electro-optic modulator (EOM), which modulates the intensity of the transmitted laser light as an approximately linear function of the voltage applied across it. This technique does not require a power supply near to the cable joints as the EO modulator is passive. In this system a fiber laser provides linearly polarized light output via an optical fiber to the EOM input, and monitors the optical output from the EOM using an optical receiver. The EO modulator is polarization dependent and by nature laser diodes give polarized light output. This system was developed to suit the concept of remote monitoring of PD activity in a cable system. Hence, a very long optical fiber is used as a means of data transmission from the laser source to the EO modulator and from the EO modulator to the optical receiver. If the cables were directly buried, the fiber optics could be installed at the same time. The installation of the fiber would be easier in tunnel installations, which are becoming more 
widely used. Any polarized light will become randomly polarized after travelling a long distance and consequently the EO modulator may not function properly and might be totally unresponsive to any electrical modulation signals. A polarization controller has therefore been included to control the polarization state of input light to the polarization dependent EO modulator. This must be tuned by hand to ensure that the modulator functions efficiently. However this is not convenient for continuous on-line monitoring as automatic data acquisition is desirable.

This paper investigates the further development of the PD optical remote sensing technique. Alternative approaches to replace the polarization controller, such as polarization maintaining (PM) fiber, polarization independent (PI) modulator, and polarization scrambler combined with fiber polarizer have been investigated. The use of a bias-free EO modulator for replacement of the modulator with an electrical bias port has also been investigated. The bias-free modulator is a device in which the bias point of the EO modulator is set to operate at about the half-intensity point. Considering a practical threephase cable circuit of several kilometers, there are many cable joints along the line. Each individual joint needs to be monitored for PD activity. Consequently a continuous PD on-line monitoring system for cable systems requires a multi-channel monitoring system. Based on this consideration various optical multiplexing techniques including using an optical switch or a fused fibre coupler have been investigated, so that one laser source can be used to provide light to several optical modulators. Finally the improved PD optical remote sensing technique has been applied to practical PD measurements on both a $132 \mathrm{kV}$ cable joint in the HV lab at the University of Southampton, $\mathrm{UK}$ and $400 \mathrm{kV}$ cable joints at Südkabel $\mathrm{GmbH}$ in Mannheim, Germany. Both the EO modulator and the optical receiver are broadband with frequency bandwidth of $2.5 \mathrm{GHz}$ and $1 \mathrm{GHz}$ respectively. Consequently the frequency response of the optical measurement system is determined by the PD sensor, which generally operates in a maximal frequency range of several hundred MHz. Previous investigation has also indicated that the optical measurement system itself does not cause measurable changes in the signal frequency characteristics [11]. Therefore in this paper, measurements and signal processing are only discussed in the time domain. Obtained results are very encouraging and indicate the viability of this technique for continuous on-line PD monitoring applications. Overall the proposed PD optical remote sensing technique has the following advantages: it is immune to any electromagnetic interference; there is very little signal transmission attenuation; it has high detection sensitivity; it is passive without a power supply requirement; it can be buried underground; it provides electrical isolation and protection to both personnel and measurement equipment; it is compact and convenient to use.

\section{THE OPTICAL REMOTE SENSING TECHNIQUE}

\subsection{IMPLEMENTATION OF AUTOMATIC OPTICAL REMOTE SENSING}

Readily available, low-cost, electro-optic modulators are normally strongly polarization dependent. For remote monitoring of PD activity in a cable system, a long optical fiber must be used as a means of data transmission from the laser source to the EO modulator and from the EO modulator to the optical receiver. Any polarized light will become randomly polarized after travelling a long distance in conventional fiber and in such case the EO modulator would not function properly and might be totally unresponsive to any electrical modulation signals. To overcome this problem a polarization controller has been included to control the polarization state of the laser light to match the polarization sensitive EO modulator, as shown in Figure 1a. This must be tuned by hand to ensure that the modulator functions efficiently. However this is not convenient for continuous online monitoring as automatic data acquisition is desirable. In this section, approaches for removing this manually operated device are considered.

\subsubsection{POLARIZATION MAINTAINING FIBER}

Various approaches were considered to replace the polarization controller. One option is to use polarization maintaining (PM) fiber instead of standard single mode (SM) fibre between the laser source and the EO modulator, as shown in Figure 1b. PM fiber is a type of single mode fiber that preserves the polarization of light as it travels through the fiber's length. For a very long cable route, very long optical fibers are needed from the laser source in the substation to the EO modulator in the cable tunnel and equally from the EO modulator to the optical receiver in the substation. The typical price of PM fiber ( $\sim$ US $\$ 13,000 / \mathrm{km}$ ) is over 30 times more expensive than SM fiber ( $\sim$ US $\$ 400 / \mathrm{km}$ ). In addition, the attenuation for the standard SMF-28 fiber of $0.2 \mathrm{~dB} / \mathrm{km}$ (at $1550 \mathrm{~nm}$ wavelength) is much less than the attenuation for the PM fiber of $2 \mathrm{~dB} / \mathrm{km}$ (at $1550 \mathrm{~nm}$ wavelength). Therefore the use of PM fiber is both uneconomical and would result in degraded signal to noise ratio when compared with the use of single mode fiber.

\subsubsection{POLARIZATION INDEPENDENT ELECTRO-OPTIC MODULATOR}

Another option is to use polarization independent (PI) EO modulators, which would allow SM fiber to be applied between the laser source and the modulator, as shown in Figure 1c. However, although feasibility studies were carried out regarding polarization independent EO modulators, so far there are very few functioning modulators of this type available on the commercial market. A polariza- 
(a)

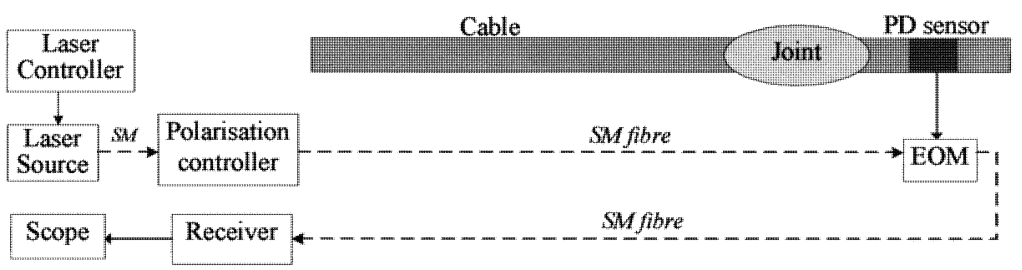

(b)

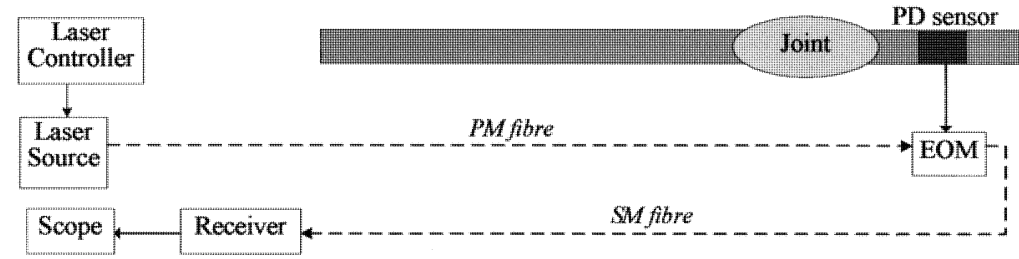

(c)
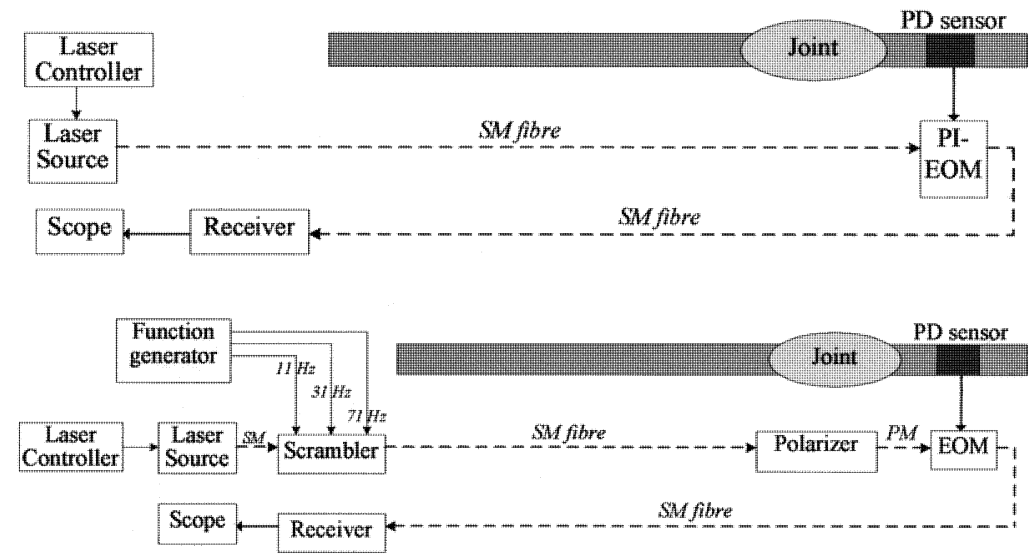

(d)

Figure 1. Optical remote sensing techniques. a, using polarization controller; b, using polarization maintaining fiber; $\mathrm{c}$, using polarization independent electro-optic modulator; $d$, using scrambler combined with in-line polarizer.

tion independent EOM was found with price of about US $\$ 20,000$, which is ten times more expensive than a standard EOM (typically less than US \$2000). For a threephase cable circuit of tens of kilometres, there would be a large number of cable joints. If a PI-EOM were required for each PD sensor at each cable joint, this option would prove prohibitively expensive.

\subsubsection{SCRAMBLER COMBINED WITH IN-LINE POLARIZER}

A revised $\mathrm{PD}$ remote optical sensing system is proposed in this paper, as shown in Figure 1d. For this research an electrically driven scrambler was applied. A polarization scrambler is a device which actively changes the state of polarization using the polarization modulation method. The scrambler manipulates the state of polarization within a single mode fiber by employing a magnetically driven fiber squeezing technique, which produces mechanical pressure sufficient to introduce a phase change in the polarization over $360^{\circ}$ in scale. The input polarization through the device can then be converted into any desired output polarization. This method also has low activation loss and no intrinsic back reflection. The scrambler is controlled by three $\pm 5 \mathrm{~V}$ input voltages each set to a unique frequency of either $11 \mathrm{~Hz}$, or $31 \mathrm{~Hz}$ or $71 \mathrm{~Hz}$.

The scrambler scrambles the linearly polarized light from the laser source and the resultant unpolarized light is then transmitted over standard SM fiber to an in-line polarizer. The polarizer is used to polarize the light and couple it into a second fiber. In principle the polarizer consists of a fiber collimator at the input end, a polarizing plate, and focusing optics on the output end. The output polarization state of the polarizer has been aligned with the input polarization requirement of the EO modulator. The polarizer has a short $0.5 \mathrm{~m}$ long polarization maintaining output fiber which is connected to the normal polarization dependent EO modulator. Both the polarizer and the EO modulator are placed close to the cable joint. The input fiber of the polarizer does not require PM fiber; therefore a long SM fiber can be used between the polarizer and the scrambler. The polarizer has a $0.8 \mathrm{~dB}$ of insertion loss. The typical price for the scrambler and the polarizer is US\$900 and US\$400 respectively. Consequently the cost of the revised optical remote sensing sys- 
(a)

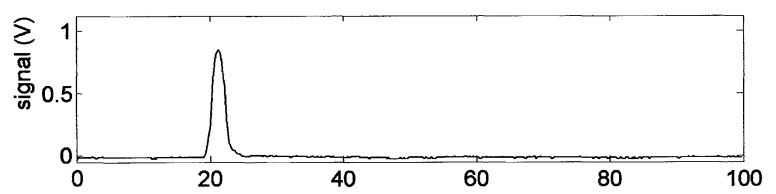

(b)

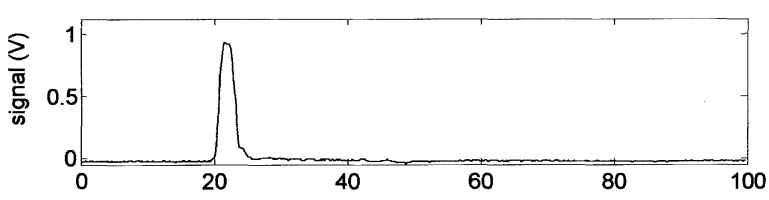

(c)

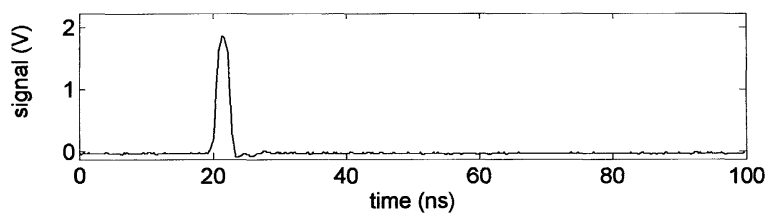

Figure 2. Optical receiver output with the pulse generator output used as the EOM input signal. a, using 'scrambler + polarizer' arrangement; b, using 'controller' arrangement; c, pulse generator output pulse.

tem is significantly reduced compared with either using polarization maintaining fiber or a polarization independent EO modulator.

Experiments were carried out to investigate the feasibility and performance of the proposed PD optical remote sensing system. Initially a pulse generator was used to provide the electrical signal input into the EO modulator. Figure 2 shows the pulse generator output pulse and the optical receiver measured pulses. Figure 2a shows the optical receiver measured pulse using experimental arrangement using scrambler and polarizer, as shown in Figure $1 d$; Figure $2 \mathrm{~b}$ shows the optical receiver measured pulse using experimental arrangement shown in Figure 1a, in this case the polarization controller was tuned to obtain the optimally polarized light for the EO modulator; Figure $2 \mathrm{c}$ is the relevant electrical pulse from the pulse generator. Obtained result indicates that there is about $10 \%$ of signal loss when the scrambler and polarizer are used instead of the polarization controller. This experiment indicates the feasibility of the proposed automatic optical remote sensing system.

\subsection{COMPARISON BETWEEN WITH-BIAS AND BIAS-FREE EO MODULATORS}

The with-bias electro-optic modulator used was a 2.5 $\mathrm{Gb} / \mathrm{siNbO}_{3}$ modulator (Aeroflex-Trilink Corp. USA). At $1550 \mathrm{~nm}$ wavelength and $25^{\circ} \mathrm{C}$, the modulator has an extinction ratio of $22 \mathrm{~dB}$, an insertion loss of $2.6 \mathrm{~dB}$, and maximal RF input voltage of $2.6 \mathrm{~V}$. It has a PM fibre input and single-mode fiber output. The modulator package has dimensions of $80 \times 10 \times 10\left(\mathrm{~mm}^{3}\right)$.

The modulator has a dc bias port and a $\mathrm{V}_{\pi}$ value of $6 \mathrm{~V}$. $\mathrm{V}_{\pi}$ is the voltage required to switch the modulator from fully off to fully on. The effect of the applied dc bias voltage on the transmitted laser light has been investigated

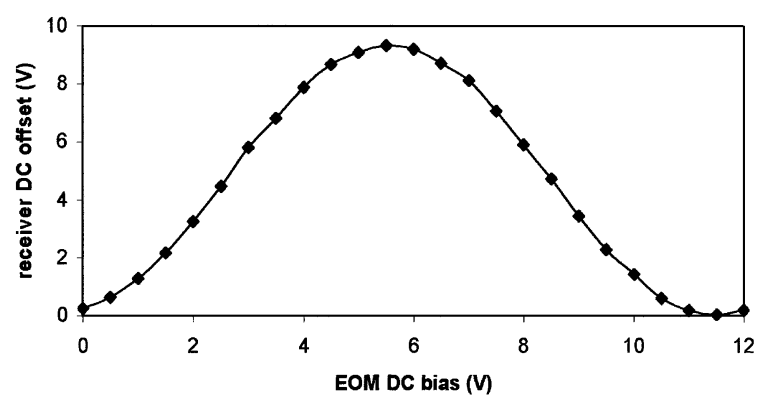

Figure 3. EOM dc bias voltage vs. photoreceiver dc bias offset (transmitted light power).

using an experimental arrangement similar to Figure 1a. In this case no signals are connected to the modulator's $\mathrm{RF}$ input port. The photoreceiver has a responsivity of $1 \mathrm{~A} / \mathrm{W}$ at a wavelength of $1550 \mathrm{~nm}$, and the gain of the dc component monitor is $10 \mathrm{~V} / \mathrm{mA}$. Consequently the photoreceiver dc component monitor has a responsivity of 10 $\mathrm{V} / \mathrm{mW}$. Obtained experimental results are shown in Figure 3. It should be noted that the phase is not balanced at $0 \mathrm{~V}$, so that $\mathrm{V}_{\pi}$ occurred at $5.5 \mathrm{~V}$ rather than $6 \mathrm{~V}$. Consequently the optimum bias point is at around $2.5 \mathrm{~V}$ and 8.5 $\mathrm{V}$ in such case.

A narrow pulse from the pulse generator with a rise time of $1 \mathrm{~ns}$ was then injected into the modulator's RF input port, with different dc voltages applied to the modulator dc bias port. The modulated signal was measured using the RF output port of the photoreceiver, as shown in Figure 4. Pulses of highest magnitude were obtained when bias voltages of around either $2.5 \mathrm{~V}$ or $8.5 \mathrm{~V}$ were applied to the modulator, and pulses of lowest magnitude were obtained when bias voltages of either $5.5 \mathrm{~V}$ or $11.5 \mathrm{~V}$ were applied. These agree with the results shown in Figure 3. A different polarity was obtained when the dc bias voltage is in the range of $0-5 \mathrm{~V}$ compared with the dc bias voltage in the range of $6-11 \mathrm{~V}$. At $5.5 \mathrm{~V}$ and $11.5 \mathrm{~V}$ the measured pulse shows both positive and negative polarities. Obtained results indicate that the modulator should be suitably biased to operate at about the half-intensity point, where a linear modulation response can be achieved and maximal sensitivity obtained.

Most commercial electro-optic modulators have a dc bias port. However, a $2.5 \mathrm{~Gb} / \mathrm{s}$ bias-free JDS Uniphase ${ }^{\circledR}$ modulator was found to replace the with-bias modulator. The bias point of the interferometer is set to operate at the half-intensity point using physical imbalance rather than an electrical bias signal. Therefore a bias control circuit is not required. The modulator has an extinction ratio of greater than $20 \mathrm{~dB}$, an insertion loss of less than 4.5 $\mathrm{dB}$, maximal $\mathrm{RF}$ input voltage of $3.5 \mathrm{~V}$, and operating wavelength between 1535 to $1565 \mathrm{~nm}$. It has a PM fiber input and single-mode SMF-28 fiber output. The packaged modulator has smaller dimensions of $45 \times 10 \times 7 \mathrm{~mm}^{3}$. 

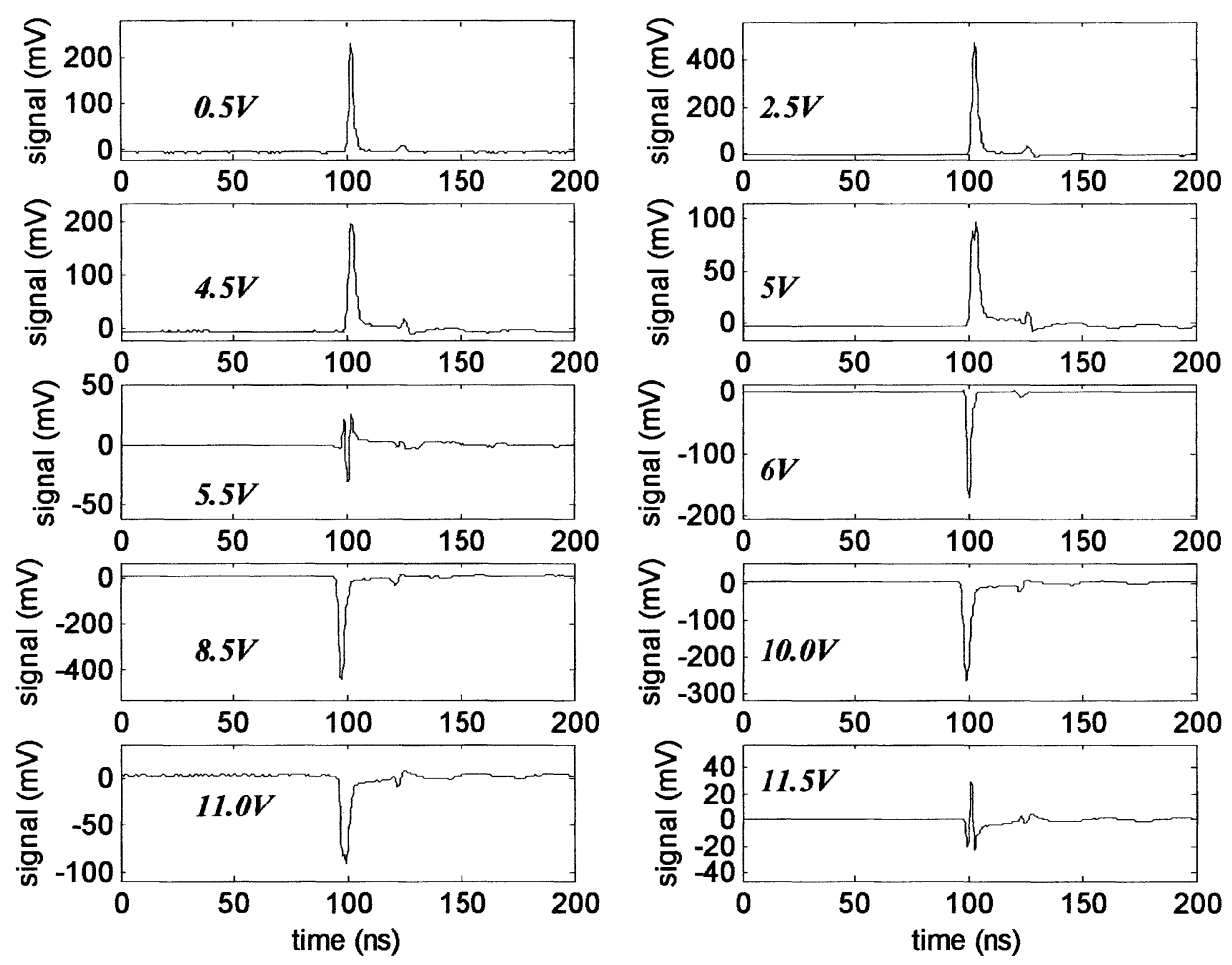

Figure 4. Effect of the dc bias voltage on the modulator performance.

Experiments were carried out to compare the performance of the bias-free modulator and the with-bias modulator. For this experiment the PM input fiber of both modulators were directly connected to the laser source. The arrangement is similar to Figure 1a except that in this case the polarization controller was removed. When the laser controller current is $200 \mathrm{~mA}$, the laser source provides an output light power of around $9 \mathrm{~mW}$, the dc monitor bias output of the photo receiver is $2 \mathrm{~V}$ for the with-bias modulator and $15 \mathrm{~V}$ for the bias-free modulator. In this case there is no RF signal input to the modulator and no $\mathrm{dc}$ bias input for the with-bias modulator. Therefore, the with-bias modulator and the bias-free modulator transmitted $0.2 \mathrm{~mW}$ and $1.5 \mathrm{~mW}$ respectively for a light input of 9 $\mathrm{mW}$, indicating that the bias-free modulator has much better light transmission performance than the with-bias modulator without applied DC bias voltage. A pulse from the pulse generator was used as the same input to the two modulator RF input ports, and subsequently measured from the photoreceiver RF output port. Figure 5 indicates that the bias-free modulator provides a signal with magnitude four times higher than the with-bias modulator (when no voltage is applied to the bias port).

\subsection{OPTICAL MULTIPLEXING TECHNIQUES}

A continuous PD on-line monitoring system for HV cable circuits must be a multi-channel monitoring system. While the principle of the optical remote sensing tech-
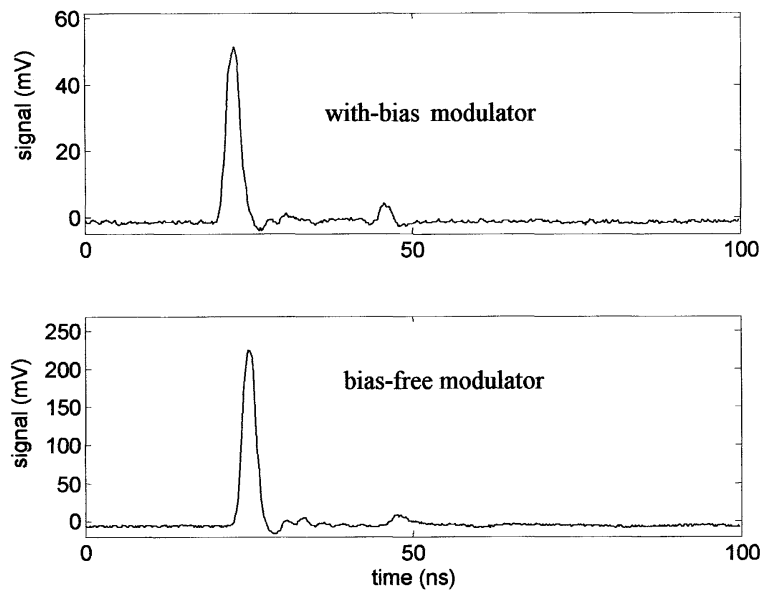

Figure 5. Comparison between the with-bias and bias-free modulator.

nique has been established, significant challenges remain in how to implement data acquisition and transmission for a multi-channel system.

The laser source used in the optical remote sensing technique is a compact single wavelength distributed feedback fiber laser designed to provide narrow line width, low relative intensity noise (RIN) and phase noise, and very good wavelength stabilization. It is suitable for use in optical sensing. However, this fiber laser source is expensive. If a multi-channel system simply consisted of many individual monitoring circuits with each circuit requiring a 
fiber laser, the whole system would be very costly. Thus various optical multiplexing techniques have been considered such that one laser source can be used to provide light to several modulators.

\subsubsection{MULTIPLEXING USING AN OPTICAL SWITCH}

An optical switch is a device that transfers light from one or multiple input ports to one or multiple output ports. In a fiber optic network, the optical switch's ability to change between light paths makes it an indispensable basic component in network construction. There are a variety of optical switches commercially available in the industry using different switching techniques, namely the opto-mechanical switch, the thermo-optic switch and the electro-optic switch. Opto-mechanical switches are the oldest type of optical switch and currently are the most widely deployed. These devices achieve switching by moving fiber or other bulk optic elements by means of stepper motors or relay arms. This causes them to be relatively slow with switching times in the $10-100 \mathrm{~ms}$ range. They can achieve excellent reliability, minimal insertion loss, and minimal crosstalk. These devices are more bulky than other alternatives, although new micro-mechanical devices overcome this. Thermo-optic switches are normally based on waveguides made in polymers or silica. For operation, they rely on the change of refractive index with temperature created by a resistive heater placed above the waveguide. Electro-optic switches are typically ferroelectric, and their operation depends on the change of refractive index with electric field. This characteristic makes them intrinsically high-speed devices with low power consumption. However, neither the electro-optic nor thermo-optic optical switches can yet match performance of opto-mechanical designs in term of the insertion loss, back reflection, and long-term stability.

Figure 6 details a multi-channel monitoring system using an optical switch. For this arrangement only one laser source is required. The optical switch acts as an optical multiplexer to enable the laser light to transmit over dif- ferent optic fibers to EO modulators. Channel selection can be performed using an external electronic control circuit attached to the switch.

The capacitive coupler works in the very high frequency range up to $300 \mathrm{MHz}$, consequently the sampling rate must be at least $600 \mathrm{MS} / \mathrm{s}$. For two capacitive couplers working at the same time, a sampling of more than $1200 \mathrm{MS} / \mathrm{s}$ is required. Therefore, the optical switch used needs to be capable of operating at a very high speed i.e. $1200 \mathrm{MHz}$ in order to capture all of the measured signals from partial discharge activities in two cable joints. Such high-speed optical switches are difficult to source. One ultra-high speed $1 \times 2$ switch was found with a switching time of less than $100 \mathrm{ps}$, insertion loss less than $3.5 \mathrm{~dB}$ and crosstalk less than $-20 \mathrm{~dB}$, at a price of US $\$ 7000$. For a similar switch with slower switching time of 10 to $100 \mathrm{~ns}$, the price is US\$4000. An additional electronic control circuit needs to be designed to work with the optical switch.

Indeed most optical switches are the opto-mechanical types having much slower switching time range of 5 to 30 $\mathrm{ms}$, though with lower prices. If such switches are used, there will be some 'lock-out' time for any of the monitoring channels. This means that any monitors relating to cable joints are not practically operating continuously but at a time interval (tens of ms). This methodology would still be able to detect insulation faults within the cable joints due to long-term degradation and prevent the occurrence of such kinds of breakdown, but it may not be able to detect faults that cause spontaneous breakdown.

\subsubsection{FUSED FIBRE OPTIC COUPLER}

Given the problems associated with using an optical switch a fused fiber optic coupler has been used to realize optical multiplexing. A fiber coupler splits optical light between two fibers, or combines optical signals from two fibers into one fiber. The fiber coupler is constructed by fusing and tapering two fibers together. This method provides a simple, rugged and compact method of splitting and combining optical signals. The used fiber coupler has a typical excess loss as low as $0.2 \mathrm{~dB}$, directivity better

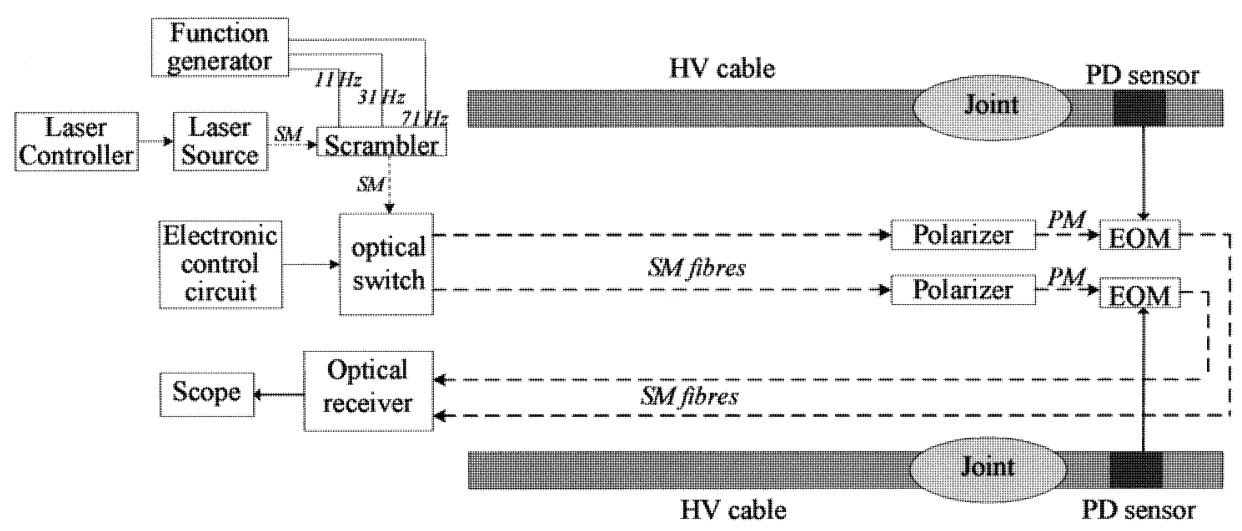

Figure 6. A multi-channel monitoring system using an optical switch. 


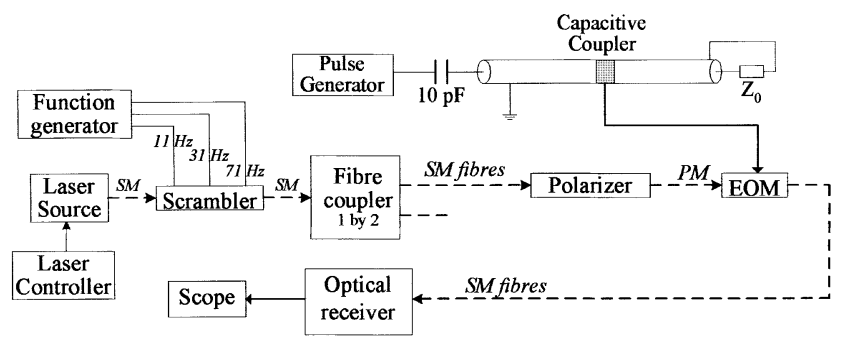

Figure 7. Arrangement to investigate the performance of the fused fiber coupler.

than $50 \mathrm{~dB}$, and splitting ratio (the ratio of power between the two output fibers) accurate to within \pm 3 percent at the design wavelength. The limitation of the fused fiber optic coupler lies in the fact that it is highly wavelength dependent. A difference in wavelength of only $10 \mathrm{~nm}$ can cause a significant change in the splitting ratio. As a result it is important to specify the exact wavelength at which the fused coupler will be used. This is not a problem for this research as the current laser source used has very good wavelength stabilization. Furthermore, for a fiber coupler made from polarization maintaining fiber, there is an additional limitation of not maintaining polarization well at the fusion point, making it sensitive to temperature or vibration. As a result it is not well suited for polarization applications. Again this is not a problem for the proposed measurement system, as the fiber coupler is fed with unpolarized light from the scrambler.

Experiments were carried out to investigate the performance of the fused fiber optic coupler, as shown in Figure 7. The PD signal is simulated by injecting a step wave with magnitude of $1 \mathrm{~V}$ and rise time of $1 \mathrm{~ns}$ from the pulse generator into a XLPE cable section via a $10 \mathrm{pF}$ capacitor. In theory the injected charge is equivalent to $10 \mathrm{pC}$, which is then measured by a capacitive coupler installed onto the cable section. The experiments were carried out in three steps: (1) the laser source was directly connected to the EOM; (2) the laser source was connected to the scrambler and then to the polarizer and EOM; (3) the laser source was connected to the scrambler, then to the fiber coupler, and finally to the polarizer and EOM. The EOM RF input is the same signal from the capacitive coupler.

Figure 8 shows the results for the three experimental arrangements. In this case, using a scrambler and polarizer reduces the signal magnitude by about $20-25 \%$ compared with the laser light being directly input into the EOM. The fibre coupler halves the light power, which results in $50 \%$ of signal magnitude measured by the optical receiver, as shown in Figures $8 \mathrm{~b}$ and $8 \mathrm{c}$.

The fused fiber coupler can be in the form of $1 \times \mathrm{N}$. Obviously the laser source should provide enough power to drive multiple paths. It is estimated that a laser source with output power of $100 \mathrm{~mW}$ may be able to drive 30 (a)

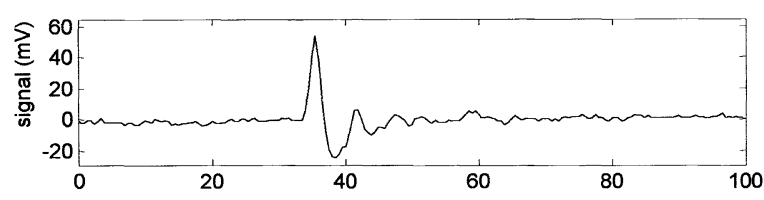

(b)

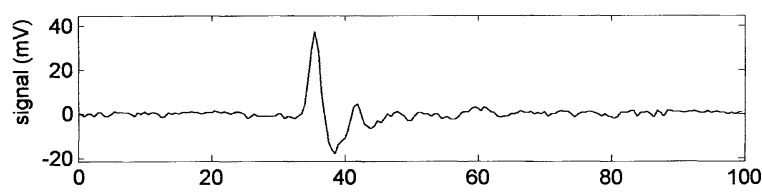

(c)

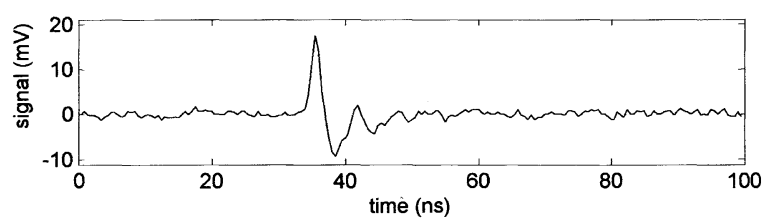

Figure 8. Simulation results using three experimental arrangements. a, laser-EOM; b, laser-scrambler-polarizer-EOM; c, laserscrambler-coupler-polarizer-EOM.

optical paths, which would correspond to 10 three-phase cable joints, if each joint is monitored using one PD sensor.

\section{PD MEASUREMENTS ON A $132 \mathrm{KV}$ CABLE JOINT}

The optical remote sensing technique has been applied to detect partial discharges produced at a $132 \mathrm{kV}$ cable/joint loop. The test arrangement is shown in Figure 9. Two $132 \mathrm{kV}$ XLPE cable sections are connected by a prefabricated cable joint. The main insulation material of the cable joint is ethylene propylene rubber (EPR), whereas the cable insulation is XLPE. The cable ends are connected to oil-filled terminations. Conventional PD electrical detection was also applied to provide the apparent discharge quantity. Conducting paint in the shape of ' $v$ ' was installed on top of the cable XLPE between the cable joint stress cone (conductor) and the cable joint outer semiconducting layer. This acted as the PD source within the cable joint. The capacitive couplers were installed on the cable section close to the cable joint.

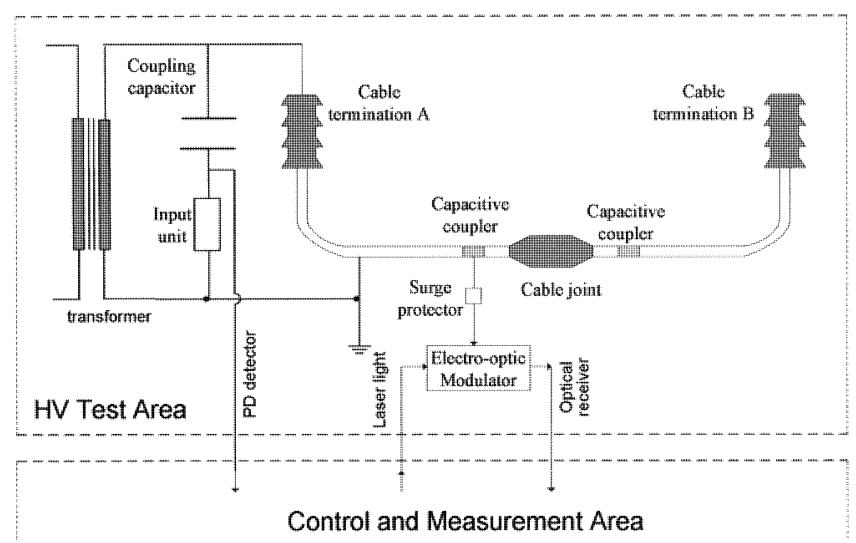

Figure 9. Application of the optical remote sensing technique to detect PDs within a $132 \mathrm{kV}$ cable joint. 

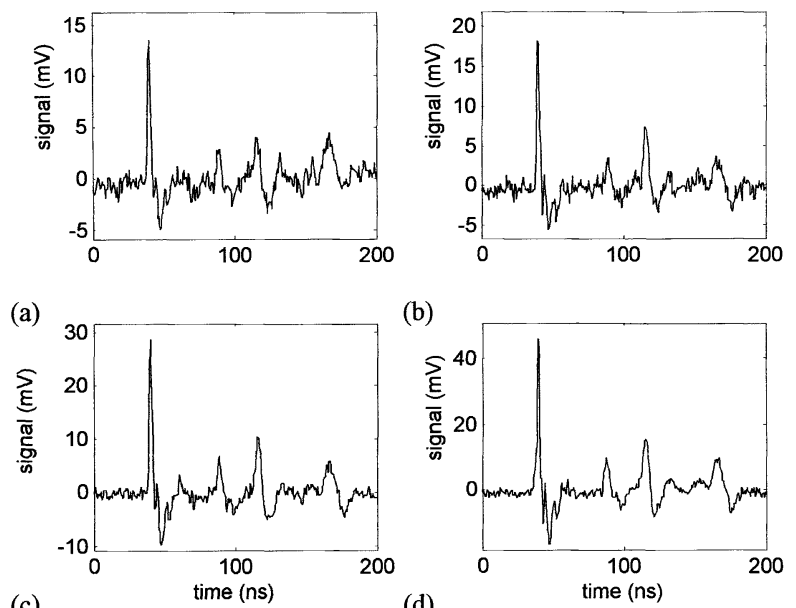

Figure 10. Practical PD signals measured using the laser - controller - 'with-bias' EOM arrangement, at different applied voltages and laser controller currents. a, $40 \mathrm{kV}, 150 \mathrm{~mA} ; \mathrm{b}, 40 \mathrm{kV}, 190 \mathrm{~mA} ; \mathrm{c}$, $60 \mathrm{kV}, 150 \mathrm{~mA} ; \mathrm{d}, 60 \mathrm{kV}, 190 \mathrm{~mA}$.

Initially the with-bias modulator was used and the experimental arrangement is as shown in Figure 1a. The laser source was connected to the polarisation controller and then to the EO modulator. PD measurements were carried out at test voltages of $40 \mathrm{kV}$ and $60 \mathrm{kV}$, with laser controlling currents of $150 \mathrm{~mA}$ and $190 \mathrm{~mA}$ respectively. Obtained results are shown in Figure 10. Concurrent PD measurements from the Robinson ${ }^{\circledR}$ PD detector reveals that the PD level is around $100-130 \mathrm{pC}$ at $40 \mathrm{kV}$, and 250 $-280 \mathrm{pC}$ at $60 \mathrm{kV}$. The laser controlling current has a significant effect on the measured signals. The larger the controller current, the higher the output light power from the laser source, and this in turn leads to larger measured signals from the optical receiver.

PD measurements were then carried out using the bias-free EOM instead of the with-bias EOM, while other
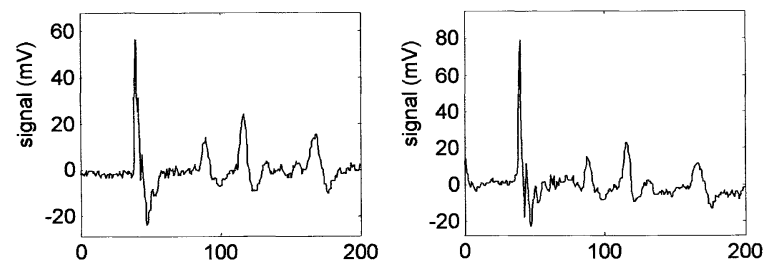

(a)

(b)

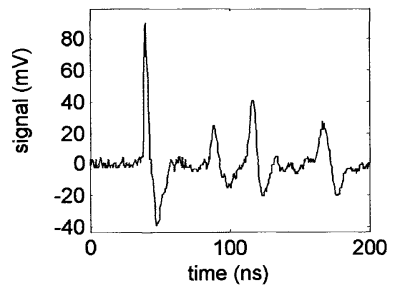

(c)

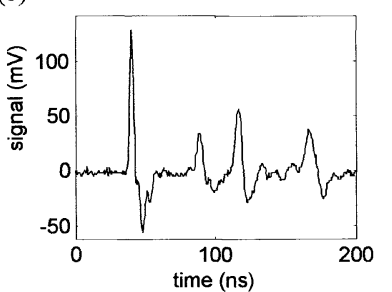

(d)

Figure 11. PD signals measured using the laser - controller - 'biasfree' EOM arrangement, at different applied voltages and laser controller currents. a, $40 \mathrm{kV}, 150 \mathrm{~mA} ; \mathrm{b}, 40 \mathrm{kV}, 190 \mathrm{~mA}$; c, $60 \mathrm{kV}, 150$ $\mathrm{mA} ; \mathrm{d}, 60 \mathrm{kV}, 190 \mathrm{~mA}$

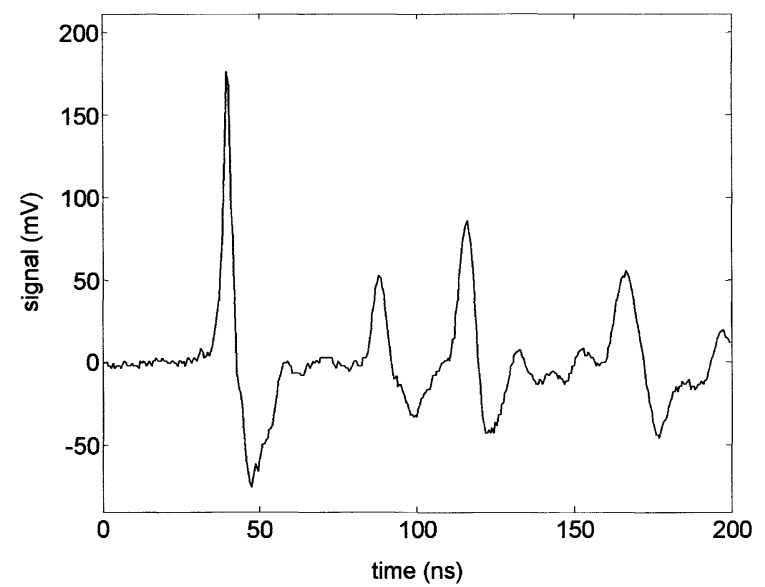

Figure 12. A capacitive coupler measured PD signal at $60 \mathrm{kV}$.

(a)

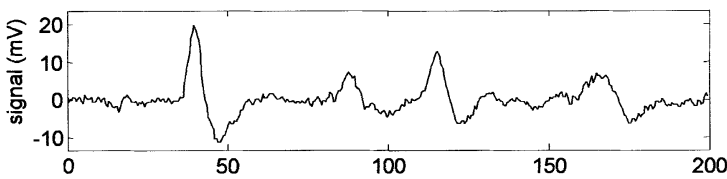

(b)

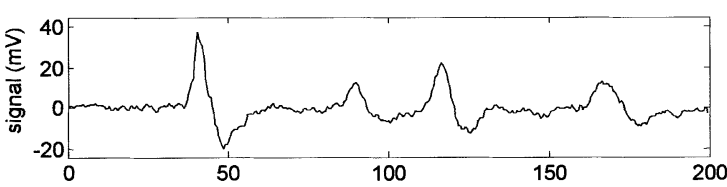

(c)

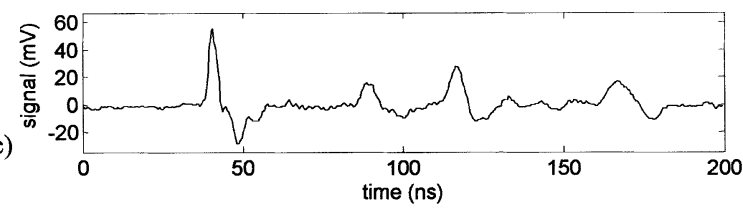

Figure 13. PD signals measured using the laser - scrambler - polarizer - 'bias-free' EOM arrangement. a, $40 \mathrm{kV}, 120 \mathrm{~mA}$; b, $40 \mathrm{kV}, 150$ $\mathrm{mA} ; \mathrm{c}, 40 \mathrm{kV}, 190 \mathrm{~mA}$

arrangements were unchanged. The obtained results (Figure 11) confirmed that the bias-free EOM has much higher measurement sensitivity than the with-bias EOM. For comparison Figure 12 shows a PD signal measured directly by the capacitive coupler at a test voltage of $60 \mathrm{kV}$. Practical PD measurements on the $132 \mathrm{kV}$ cable joint was then carried out using the scrambler combined with polarizer arrangement, as shown in Figure 1d. In this case the EOM used is the bias-free modulator. The obtained results are shown in Figure 13. Again concurrent PD measurements from the Robinson ${ }^{\circledR}$ PD detector reveals that the PD level is around $100-130 \mathrm{pC}$ at $40 \mathrm{kV}$. In this case the use of scrambler and polarizer also reduces the measured PD signal. Since PD is a stochastic process, it is difficult to establish an accurate reduction percentage for practical PD measurements. However, analysis of the signal to noise ratio indicates that the measurement sensitivity is still very good, around $5-10 \mathrm{pC}$ in this case.

Figure 14 shows the PD signal measured by the optical receiver and the PD conventional detector respectively, at a test voltage of $40 \mathrm{kV}$, using the laser - scrambler - polar- 

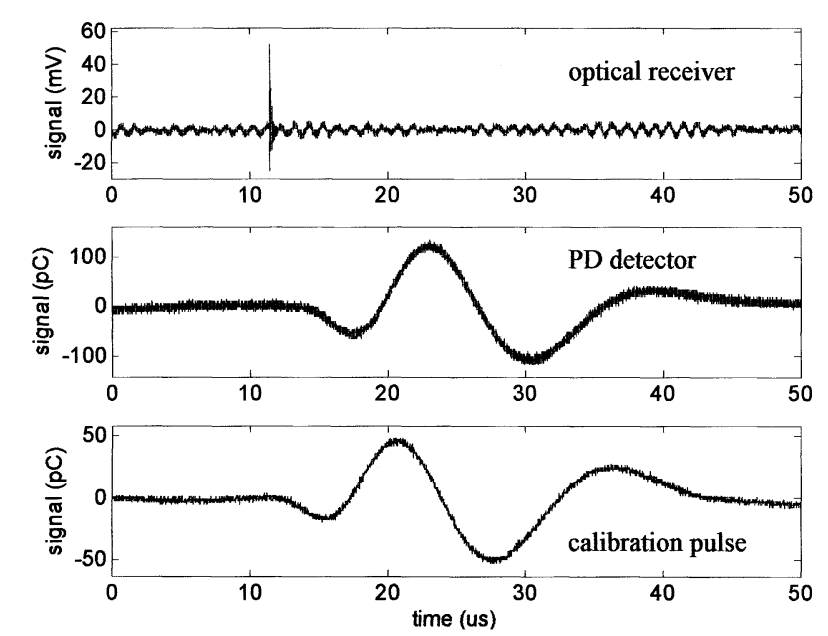

Figure 14. PD signals measured by the optical receiver, conventional PD detector, and the $50 \mathrm{pC}$ calibration pulse.

izer - bias free EOM arrangement. In this case the sampling rate is $500 \mathrm{MS} / \mathrm{s}$ ( 25,000 points on $50 \mu$ s time scale). The $50 \mathrm{pC}$ calibration pulse from the conventional PD detector is also provided. Obtained results indicate that the discharge quantity is around $120 \mathrm{pC}$. The PD signal is presented as a sharp pulse from the optical receiver, but as an extended integrated waveform from the PD conventional detector, which only works in the frequency range up to several hundred $\mathrm{kHz}$.

The fused fiber optic coupler was then included into the system. The measurement arrangement is similar to that shown in Figure 7, except that in this case practical PD signals from the $132 \mathrm{kV}$ cable joint were fed into the EOM RF input port. Obtained measurement results are shown in Figure 15. Compared with Figure 13, obtained results confirm that the fused fiber optic coupler generally splits the light power equally, and this in turn results in a

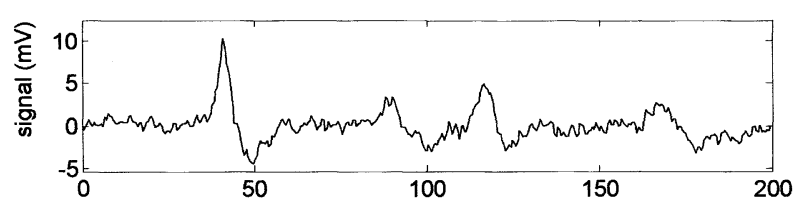

(a)

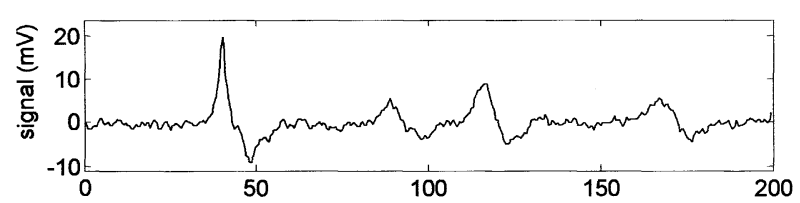

(b)

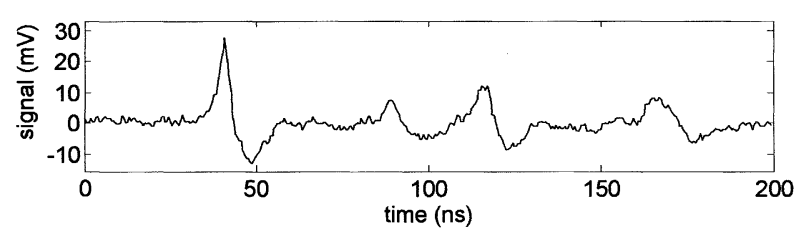

Figure 15. PD signals measured using the laser - scrambler - fibre coupler - polarizer - 'bias-free' EOM arrangement. a, $40 \mathrm{kV}, 120 \mathrm{~mA}$; b, $40 \mathrm{kV}, 150 \mathrm{~mA}$; c, $40 \mathrm{kV}, 190 \mathrm{~mA}$.

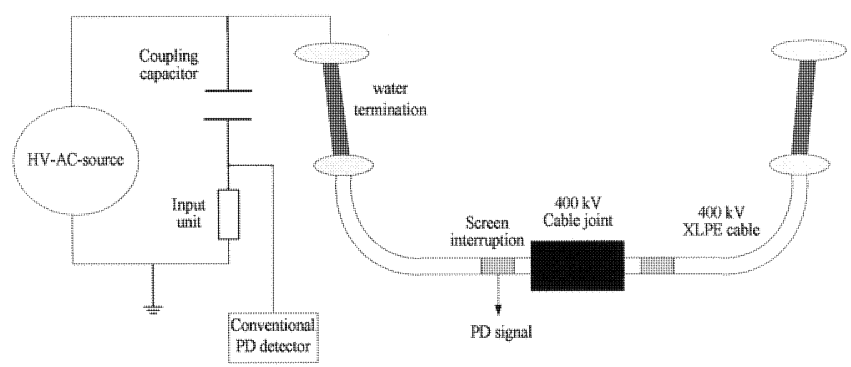

Figure 16. PD measurements on $400 \mathrm{kV}$ cable joint loop with water terminations.

reduction of about $50 \%$ of practically measured PD signal magnitude.

\section{PD MEASUREMENTS ON $400 \mathrm{kV}$ CABLE JOINTS}

Practical PD measurements were also carried out on $400 \mathrm{kV}$ cable joints in the High Voltage Laboratory at Südkabel GmbH, Germany. Figure 16 shows the test setup of the $400 \mathrm{kV}$ cable/joint loop. The Haefely RSZC ac voltage test system, which consists of a series resonant circuit, is specially designed for type testing of high voltage cables. It has a rated voltage of $700 \mathrm{kV}$ and rated power of $29000 \mathrm{kVA}$. The prefabricated cable joint and PD sensor is shown in Figure 17. The prefabricated composite joint type is applied for voltages from $220 \mathrm{kV}$ to $400 \mathrm{kV}$. It consists of an insulating body made of epoxy-resin with an integrated field control electrode. The 'high voltage sealing' of the cable to the joint body is achieved by stresscones made from silicon rubber with an integrated stress control using a deflector. The stress cone is mechanically pre-loaded by means of a metal spring device. The earth of the prefabricated joint is isolated from the XLPE cable earth, indicating that the PD sensor is of the form of a screen interruption. PD conventional electrical measurement using a Robinson ${ }^{\circledR}$ Model 5 detector was also applied to provide a measurement of apparent charge in $\mathrm{pC}$.

The cable/joint loop was energized and the PD inception voltage was found to be $41 \mathrm{kV}$. The voltage was increased to $186 \mathrm{kV}$ and this produced PDs of $30 \mathrm{pC}$ that

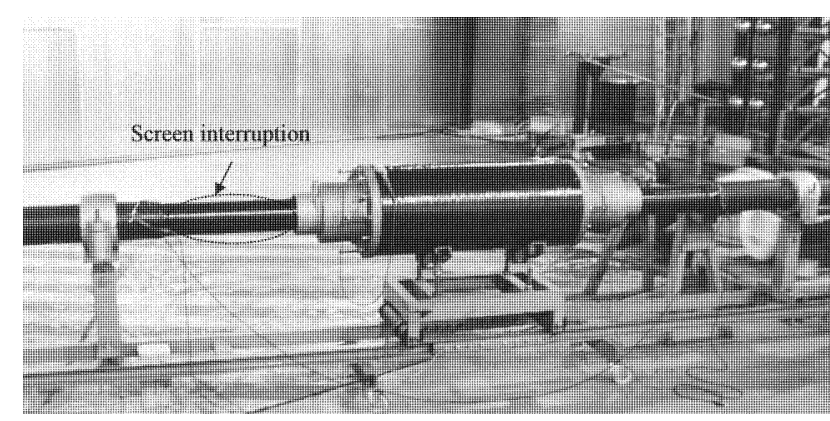

Figure 17. The prefabricated cable joint and screen interruption PD sensor. 


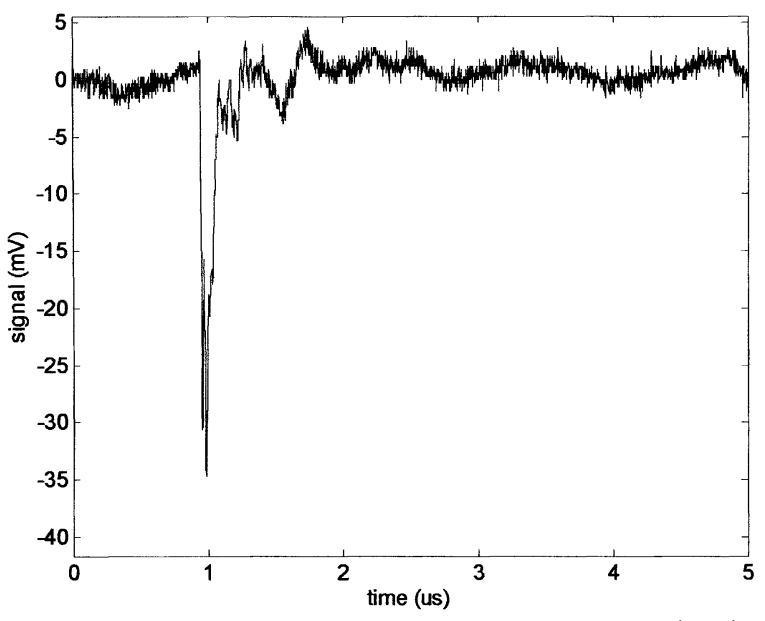

Figure 18. PD signal due to a real production defect (void) between stress shield and epoxy resin within the cable joint, measured using the laser - controller - 'bias-free' EOM arrangement.

were detected using the measuring arrangement including laser-controller-EOM-photoreceiver (Figure 1a). The obtained result is shown in Figure 18. After-test inspection indicated that the PD activity was due to a practical production defect (void) between the cable conductor and the epoxy resin within the cable joint.

The $400 \mathrm{kV}$ cable joint was replaced with an alternative one of the same type and the loop was re-energized. It was PD free for an applied voltage of $250 \mathrm{kV}$. Four metal wires were then placed on the surface of the stress cone near to the cable conductor, as shown in Figure 19 and the joint reassembled. PD measurements were then carried out using the laser-scrambler-polarizer-EOM arrangement (Figure 1d). High voltage was applied to the

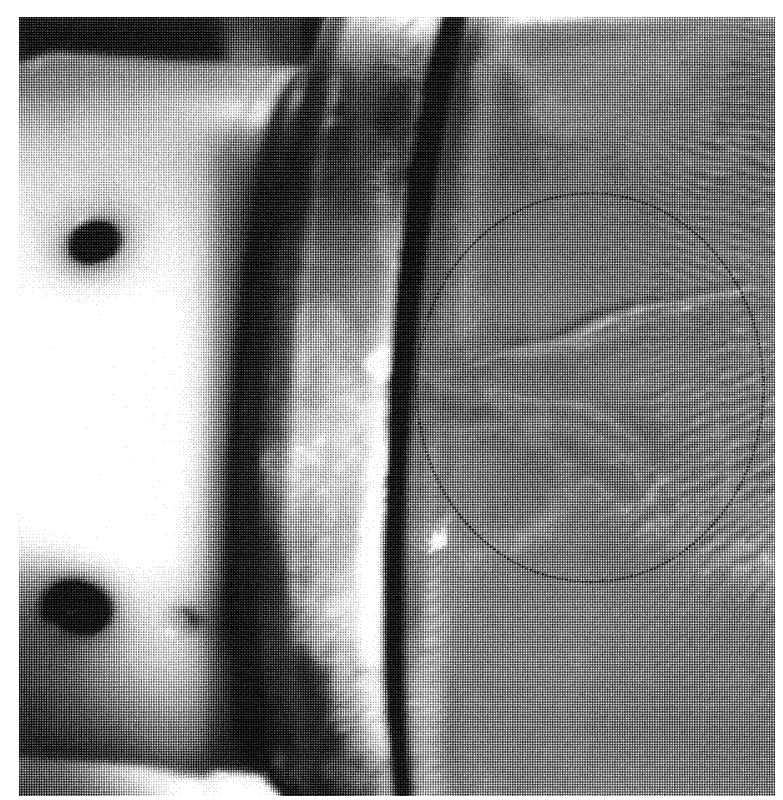

Figure 19. Metal wires on the stress relief cone within the cable joint as PD source.

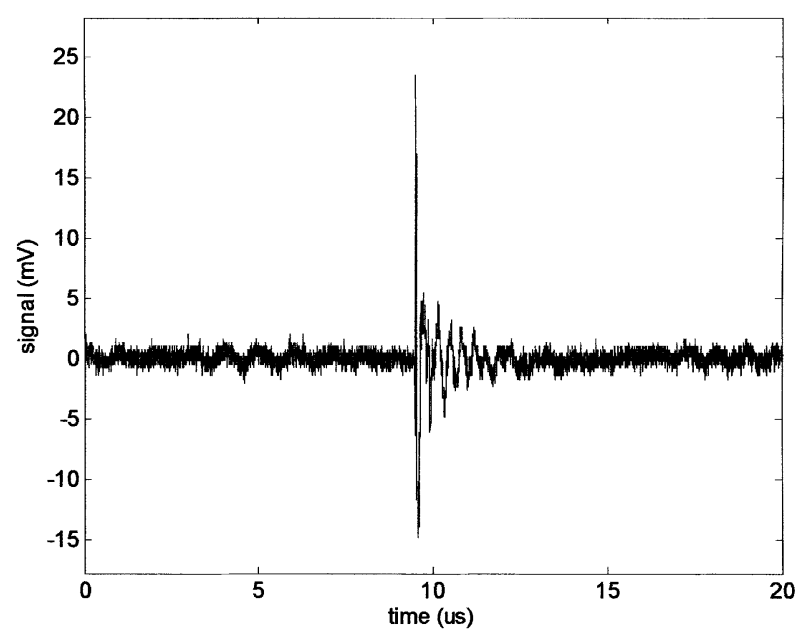

Figure 20. PD signal due to metal wires within the cable joint, measured using the laser - scrambler - polarizer - 'bias-free' EOM arrangement.

loop and in this case the PD inception voltage was found to be $13 \mathrm{kV}$. The voltage was further increased and measurement was carried out at $70 \mathrm{kV}$, as shown in Figure 20. The conventional PD detector indicates that in this case the PD level was $20-30 \mathrm{pC}$.

The wires were then removed and copper filings were placed about halfway along the stress cone, as shown in Figure 21. PD measurements were also carried out using the laser-scrambler-polarizer-EOM arrangement. In this case the PD inception voltage was found to be $180 \mathrm{kV}$ and at $480 \mathrm{kV}$ PDs of $10-12 \mathrm{pC}$ were generated and consequently measured, as shown in Figure 22. Further analysis of the measurement data revealed that the background noise is caused by the optical system itself having a resonant frequency up to $1 \mathrm{MHz}$. Therefore measurement sensitivity could be increased by using a high pass filter to attenuate lower frequency signals.

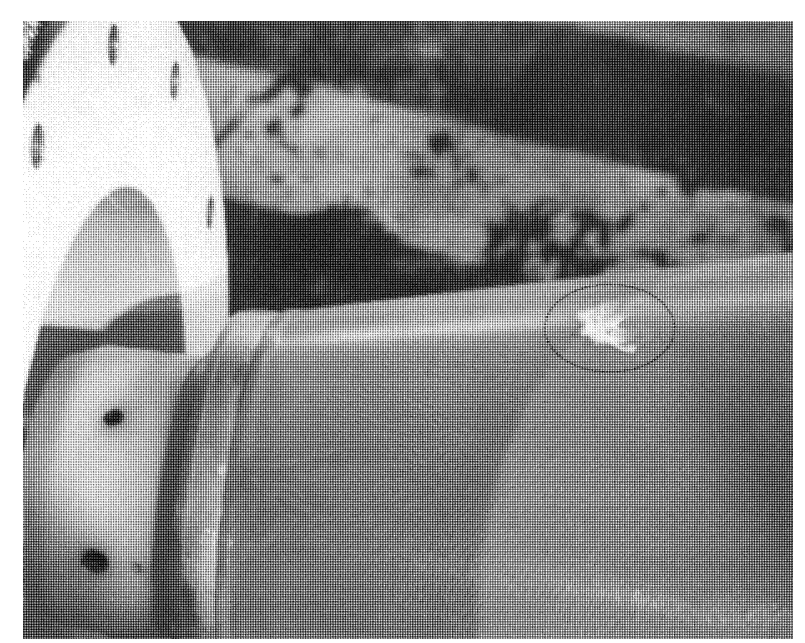

Figure 21. Copper filings on the stress relief cone within the cable joint as PD source. 


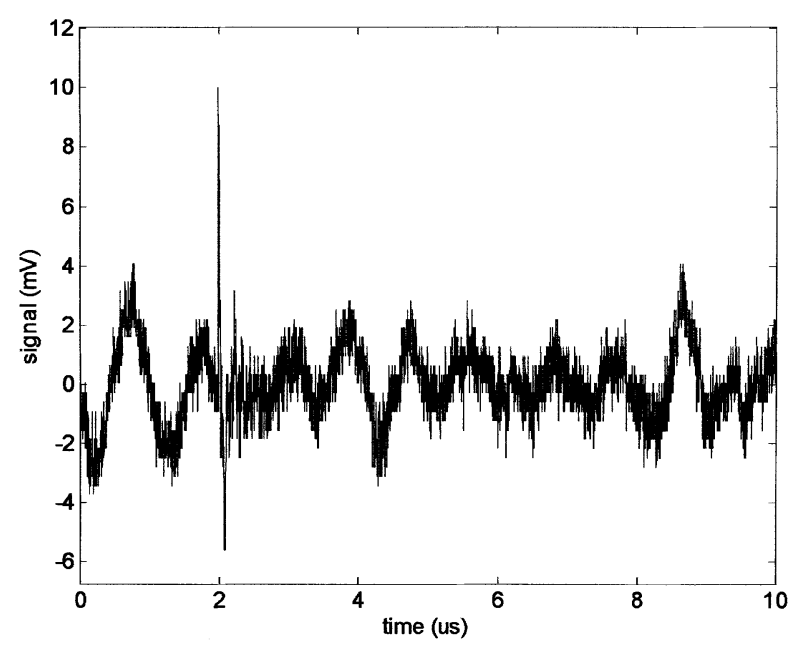

Figure 22. PD signal due to copper filings within the cable joint, measured using the laser - scrambler - polarizer - 'bias-free' EOM arrangement.

\section{CONCLUSIONS}

This paper has described the continued development of the electro-optic modulator based PD detection technique. Based on considerations of overall cost, feasibility and convenience, the revised measuring system requires a laser source, polarization scrambler, standard single mode fibers, in-line fibre polarizer, bias-free EO modulator and optical receiver. Both the polarizer and bias-free EO modulator, which are placed near cable joints, are passive without any additional power requirements. The bias-free EO modulator, which operates near the half-intensity point, has proved to have better light transmission performance and higher measurement sensitivity than the previously used with-bias modulator. A fused fiber optic coupler was used to allow optical multiplexing by splitting laser light equally to several optical paths, and the feasibility and effectiveness of this approach have been verified. In this way the number of required laser sources could be reduced to implement multi-channel monitoring. Practical PD measurements on both a $132 \mathrm{kV}$ cable joint at the University of Southampton, UK, and $400 \mathrm{kV}$ cable joints at Südkabel GmbH, Germany, have verified the principle and demonstrated the effectiveness of the developed technique. Obtained results indicate that partial discharges of $10-15 \mathrm{pC}$ can be clearly measured using the optical remote sensing technique. The developed technique can also be used to monitor cable terminations within substations. However, as mains supply in a substation is easily available, the biggest advantage of this technique, i.e. the nature of being 'passive', is not fully utilized. The measurement sensitivity of this technique could be further increased by applying suitable filters and amplifiers to process the optical receiver output signals and remove any inherent noise of the measuring system. Application of passive amplifiers such as radio frequency transformers to amplify the PD sensor-measured signal before feeding into the electro-optic modulator could also help to increase the signal to noise ratio of the measuring system.

For practical applications the optical measuring system may need to be calibrated to relate the measured signal in $\mathrm{mV}$ to a discharge apparent quantity in $\mathrm{pC}$. In this paper the sensitivity check of the measurement system is carried out by comparing with the conventional PD detector which provides a discharge quantity in $\mathrm{pC}$. However, this would not be practical for on-line applications. It might be very difficult to have an accurate calibration but the capability to estimate the discharge level, i.e. $10 \mathrm{~s}$ or $100 \mathrm{~s}$ of $\mathrm{pC}$, would be valuable for continuous monitoring applications where trends are important rather than absolute discharge values. Finally it would also be valuable to investigate the feasibility of implementing non-linear polymeric materials acting as optical modulators designed into the fabric of the cable joint itself.

\section{ACKNOWLEDGEMENTS}

The authors would like to thank Südkabel GmbH, Germany for the permission to carry out PD measurements on the $400 \mathrm{kV}$ cable joints. In particular we would like to thank Mrs. Astrid Taernhuvud and Dr. Johannes Kaumanns for their help. We would also like to thank Prof. Peter Smith and Dr. Trevor Newson of the Optoelectronics Research Centre at the University of Southampton, UK for technical advice. The financial support from National Grid Transco plc, UK for this project is gratefully acknowledged.

\section{REFERENCES}

[1] Y. Tian, P. L. Lewin, J. S. Wilkinson, S. J. Sutton and S. G. Swingler, "Continuous Online Monitoring of Partial Discharges in High Voltage Cables", IEEE Intern. Sympos. Electr. Insul. (ISEI), Indianapolis, USA, pp. 454-457, 2004.

[2] Y. Tian, P. L. Lewin, A. E. Davies, S. J. Sutton and S. G. Swingler, "Partial Discharge Detection in Cables Using VHF Capacitive Couplers", IEEE Trans. Dielectr. Electr. Insul., Vol. 10, pp. 343-353, 2003.

[3] Y. Tian, P. L. Lewin, A. E. Davies, S. G. Swingler, S. J. Sutton and G. M. Hathaway, "Comparison of On-line Partial Discharge Detection Methods For HV Cable Joints", IEEE Trans. Dielectr. Electr. Insul., Vol. 9, pp. 604-615, 2002.

[4] C. G. Henningsen, K. Polster, B. A. Fruth and D. W. Gross, "Experience with an On-Line Monitoring System for $400 \mathrm{kV}$ XLPE Cables", Record of IEEE T\&D Conf., pp. 515-520, Los Angeles, USA, 1996.

[5] Y. Tian, P. L. Lewin, M. Webb, S. J. Sutton and S. G. Swingler, "Continuous Monitoring of Partial Discharges in Power Cables using Capacitive Couplers and Trend Analysis", Proc. of 13th International Symposium on High Voltage Engineering (ISH), Delft, the Netherlands, 2003.

[6] Y. Tian, P. L. Lewin, A. E. Davies, S. J. Sutton and S. G. Swingler, "Partial Discharge Detection in Cable Systems using Very High Frequency Capacitive Coupler and Screen Interruption Techniques", IEEE 14th Intern. Sympos. Electr. Insul. (ISEI), Boston, USA, pp. 87-90, 2002.

[7] N. H. Ahmed and N. N. Srinivas, "On-line Partial Discharge Detection in Cables", IEEE Trans. Dielectr. Electr. Insul., Vol. 5, pp. 181-198, 1998. 
[8] R. Plath, U. Herrmann, K. Polster, J. Spiegelberg and P. Coors, "After Laying Tests of $400 \mathrm{kV}$ XLPE Cable Systems for Bewag Berlin", 11th International Symposium on High Voltage Engineering (ISH), Vol. 5, pp. 276-279, London, UK, 1999.

[9] H. Ota, M. Ichihara, N. Miyamoto, S. Kitai, Y. Maruyama, M. Fukasawa and H. Takehana, "Application of Advanced Afterlaying Test to Long-distance $275 \mathrm{kV}$ XLPE Cable Lines", IEEE Trans. Power Delivery, Vol. 10, pp. 567-579, 1995.

[10] Y. Tian, P. L. Lewin, A. E. Davies and G. Hathaway, “Acoustic Emission Techniques for Partial Discharge Detection within Cable Insulation", Proceedings of 8th International Conference on Dielectric Materials, Measurements and Applications (DMMA), Edinburgh, UK, pp. 503-508, 2000.

[11] Y. Tian, P. L. Lewin, D. Pommerenke, J. S. Wilkinson and S. J. Sutton, "Partial Discharge On-line Monitoring for HV Cable Systems using Electrooptic Modulators", IEEE Trans. Dielectr. Electr. Insul., Vol. 11, pp. 861-869, 2004.

[12] J. Wilson and J. Hawkes, Optoelectronics, Published by Prentice Hall Europe, 1998.

[13] A. Yariv, "Optical Electronics in Modern Communications", Oxford University Press, 1997.

[14] D. J. R. Harry, Understanding Optical Communications, Published by Prentice PTR, 1998.

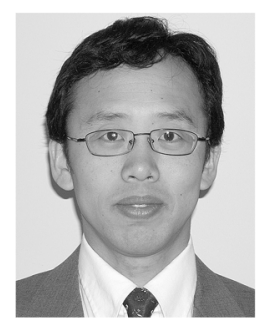

Yuan Tian was born in Liaoning, China in 1970. He received the B.Sc. and M.Sc. degrees in electrical engineering from Xi'an Jiaotong University and Shenyang University of Technology, China, in 1992 and 1995, respectively. He obtained the Ph.D. in electrical engineering from the University of Southampton, UK in 2001. Since January 2001 he has been a research fellow in the Electrical Power Engineering at the University of Southampton. His main research interests include partial discharge measurements, condition monitoring and diagnosis of $\mathrm{HV}$ cables and power plant, optical remote sensing techniques, non-destructive testing techniques including acoustic emission techniques, space charge measurements in dielectrics and applied signal processing techniques. He has published about 40 refereed conference and journal papers in these research areas.

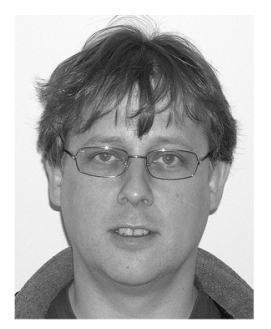

Paul Lewin was born in Ilford, Essex in 1964. $\mathrm{He}$ received the B.Sc. (Hons) and Ph.D. degrees in electrical engineering from the University of Southampton, UK in 1986 and 1994, respectively. He joined the academic staff of the University in 1989 and at present is the Reader in Electrical Power Engineering in the School of Electronics and Computer Science. His research interests include condition monitoring of $\mathrm{HV}$ cables and plant, surface charge measurement, HV insulation/dielectric materials and applied signal processing. Since 1996 he has published over 80 refereed conference and journal papers in these research areas. He is the manager of the Tony Davies High Voltage Laboratory at the University of Southampton.

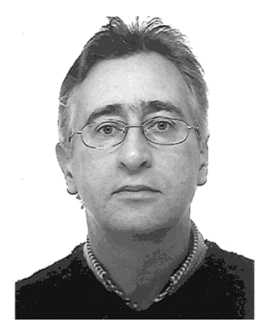

James Wilkinson received the B.Sc. (Eng.) degree in electronics in 1977 and the Ph.D. degree in the field of integrated optics in 1985, both from the University College London. From 1977 to 1979 he was with the GEC Hirst Research Centre working on optical fibre telecommunications systems. From 1983 to 1985 he was with the Department of Nephrology of St Bartholomew's Hospital, London, working on sensing and control for haemodialysis procedures. He is now Professor of Optoelectronics in the School of Electronics \& Computer Science, University of Southampton, UK. He is partially seconded to the Optoelectronics Research Centre, where he leads the Integrated Optics and Microstructures Group investigating integrated optical devices including chemical and biochemical sensors with particular application to water quality monitoring, and planar waveguide lasers and amplifiers.

Gero Schröder is the manager of the R\&D Laboratory at Südkabel $\mathrm{GmbH}$ in Mannheim, Germany.

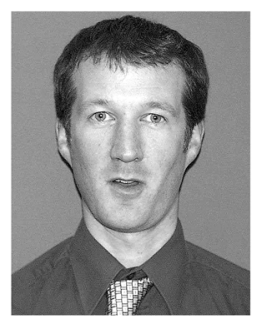

Simon Sutton received the B.Sc. and the Ph.D. degrees in physics from the University of Reading in the UK. He also holds MinstP, CSci and CPhys. He has worked for National Grid Transco since 1996 and has held various positions within the company, including Cable Policy Team Leader, and currently is the Condition and Capability Team Leader based at their Head Office in Warwick, UK. His responsibilities include the thermal rating of equipment and the policy and application of condition monitoring to both electricity and gas assets at NGT.

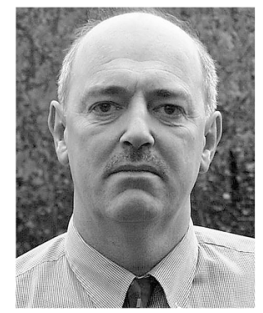

Steve Swingler received the B.A. and Ph.D. degrees in physics from the University of Lancaster. In 1976 he was appointed Pirelli Postdoctoral Research Fellow at Southampton University, investigating dielectrics for superconducting cable and extruded dc cables. He joined the Central Electricity Research Laboratories at Leatherhead in 1979 working mainly on novel cable systems and insulating materials. In 1990 he transferred to the National Grid Company, becoming Cables Manager and then Company Undergrounding Adviser. In 2003 he joined the School of Electronics \& Computer Science at Southampton University as Professor in Transmission Asset Engineering. He is the UK Member of CIGRE Study Committee B1 (High Voltage Cables). 